\title{
Evaluation and Modelling of Traffic Noise on the Asian Highway in Golestan National Park, Iran
}

\author{
Shiva Gharibi ${ }^{1}$, Mozhgan Aliakbari ${ }^{2}$, Abdolrassoul Salmanmahiny ${ }^{1}$ and Hossein Varastehe ${ }^{1}$ \\ ${ }^{1}$ Gorgan University, Gorgan, Iran, \\ ${ }^{2}$ RMIT University,Melbourne ,Australia
}

\begin{abstract}
The increasing number of vehicles on Iran's highways and major roads has led to an increase in noise levels. As a result, traffic is now considered a main source of noise pollution. This paper reports on the modelling of traffic noise levels in Golestan National Park, Golestan using vehicle data and other environmental features. For the evaluation of noise and the recording of independent environmental variables, Sampling stations were selected using a systematic-random method at 76 points at various distances and between 0-250 meters from the road. At each sampling point, traffic flow (number and speed of vehicles, number of horn beeps) was measured for 15 minutes from 8 am to $8 \mathrm{pm}$. Simultaneously other environmental variables were assessed, including the geometry of the road surface and location conditions. The best multivariable regression based on the correlation coefficient $(\mathrm{R})$ and the coefficient of determination (R2) was achieved. The R-square (73\%) and the adjusted R-square (68\%) of the regression equation were $73 \%$ and $68 \%$ respectively. The results of modelling show that the most important variables affecting noise pollution are distance from the road, roughness coefficient, speed of medium-weight vehicles, relative humidity, and height and number of light vehicles. There is a negative correlation with distance from the road and noise pollution. The accuracy of the model was found to be about $\pm 5 \mathrm{~dB}$. Therefore, the model is suggested for the prediction of traffic noise on the Asian Highway in Golestan National Park.
\end{abstract}

\section{Introduction}

Environmental noise is a worldwide problem, and noise is becoming an increasingly omnipresent, yet unnoticed, form of pollution, even in developed countries [1]. The sources of noise are broadly divided into two parts: industrial and non-industrial. Noise originates from human activities, especially the development of transport and industry. Road traffic noise is a non-industrial noise that is the most widespread source of noise in all countries and the most prevalent cause of annoyance and interference. It is directly proportional to the volume of vehicles. According to Fig. 1, noise generated by vehicular traffic is the most important source of noise [1].

However, noise from road traffic can be measured or predicted by using a common model and prediction model [2] .Both models are helpful tools to evaluate traffic noise conditions and traffic noise analysis while prediction models are important tools for planning and design of new roads/highways. Traffic engineers often compare traffic to a fluid, assuming that a certain volume must flow through the road system. Traffic noise prediction models in the 1950s and 1960s were designed to predict a single-vehicle sound pressure level (Lp) at the roadside. Later models were not intended to predict single vehicle levels [3]. Traffic noise can be either measured or predicted in the case of noise pollution management. Ref [2] Since noise measurement is complicated and timeconsuming, and moreover impossible at the design stage , traffic noise prediction models are required for the design of new highways and other roads or the redesign of traffic flow on existing roads in order to achieve comfortable traffic noise conditions. In the last few years, a number of prediction tools have been created to estimate noise levels in several countries [4].

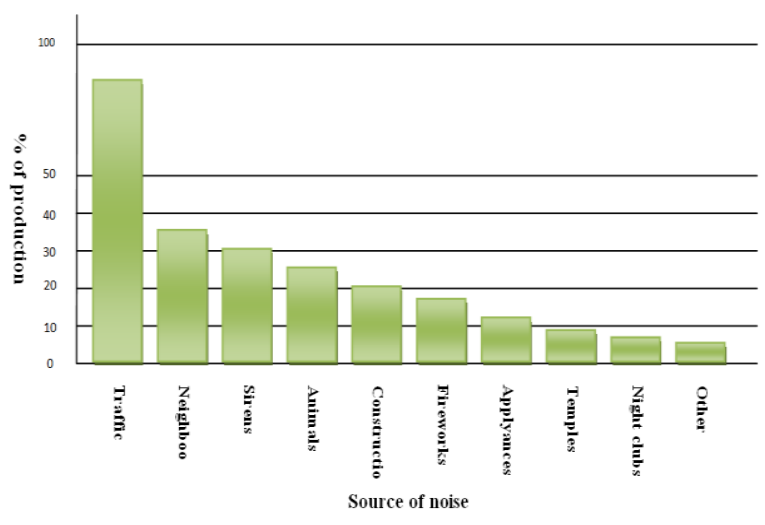

Figure 1. The most important sources of noise [1]. 


\section{Different prediction models}

Traffic noise is a component of environmental noise and is the result of the sum of various types of noise from traffic sources (e.g., cars, buses, trains, etc.). There are many parameters directly or inversely correlated with traffic noise levels [5]. For example, increased traffic volume, in terms of vehicles per hour, causes an increase in the noise level [6]. The models based on the correlation between traffic and geometrical parameters, with the Leq (equivalent continuous sound pressure level in $d B$ )measured in experimental studies, generally have as input the traffic flow, the composition and the average speed of the vehicular current, slope, the ratio between the height and the distance of the barriers and sometimes the road bed conditions [7].

The most important variables considered in the development of mathematical models are traffic flow rate and composition [1].The earliest road traffic noise model was that given in the 1952 Handbook of Acoustic Noise Control. It was offered for speeds of $35 \pm 45 \mathrm{mph}$ and distances greater than 20 feet [3]. Lam and Tam (1998) in Hong Kong developed a noise prediction tool using the Monte-Carlo technique Ref [4] taking into account traffic flow, traffic speed and traffic composition in terms of percentage of heavy vehicles.

Reed [8] used a SPreAD-GIS tool for modelling spatial patterns of anthropogenic noise propagation in natural ecosystems. The SPreAD-GIS incorporates commonly available datasets on land cover, topography, and weather conditions to calculate noise propagation patterns. Ref [5] describes the development of a model for assessing TRAffic Noise EXposure (TRANEX) in an open-source geographical information system and high correlation was seen between modelled and measured $\mathrm{L}_{\text {eq }}$.

Therefore, since each of the current noise prediction models only a few variables and there is no model for the natural environment in Iran, a model is required to predict traffic noise on the Golestan Road taking into account all variables affecting the noise of traffic.

\section{Methodology}

Figures and tables, as originals of good quality and well contrasted, are to be in their final form, ready for an operational process to develop a prediction model based on characteristics influencing the equivalent noise level has been defined and is shown in Figure 2.

\subsection{Study area}

Golestan National Park is the first national park in Iran and in the classification of protected areas in the World Conservation Union for the conservation of nature and natural resources it is in second place [9]. This park was determined as a National Park in 1967 and was selected as a biosphere reserve in 1976 [10]. It is located in the northeast of Iran and between the $37^{\circ} 16^{\prime} 43^{\prime \prime}-37^{\circ} 31^{\prime}$

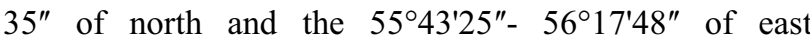
longitude, and covers 91.895 hectares. The park is located between three provinces: Golestan, Khorasan and Semnan [11]. Fig. 3 shows a view of the study area.

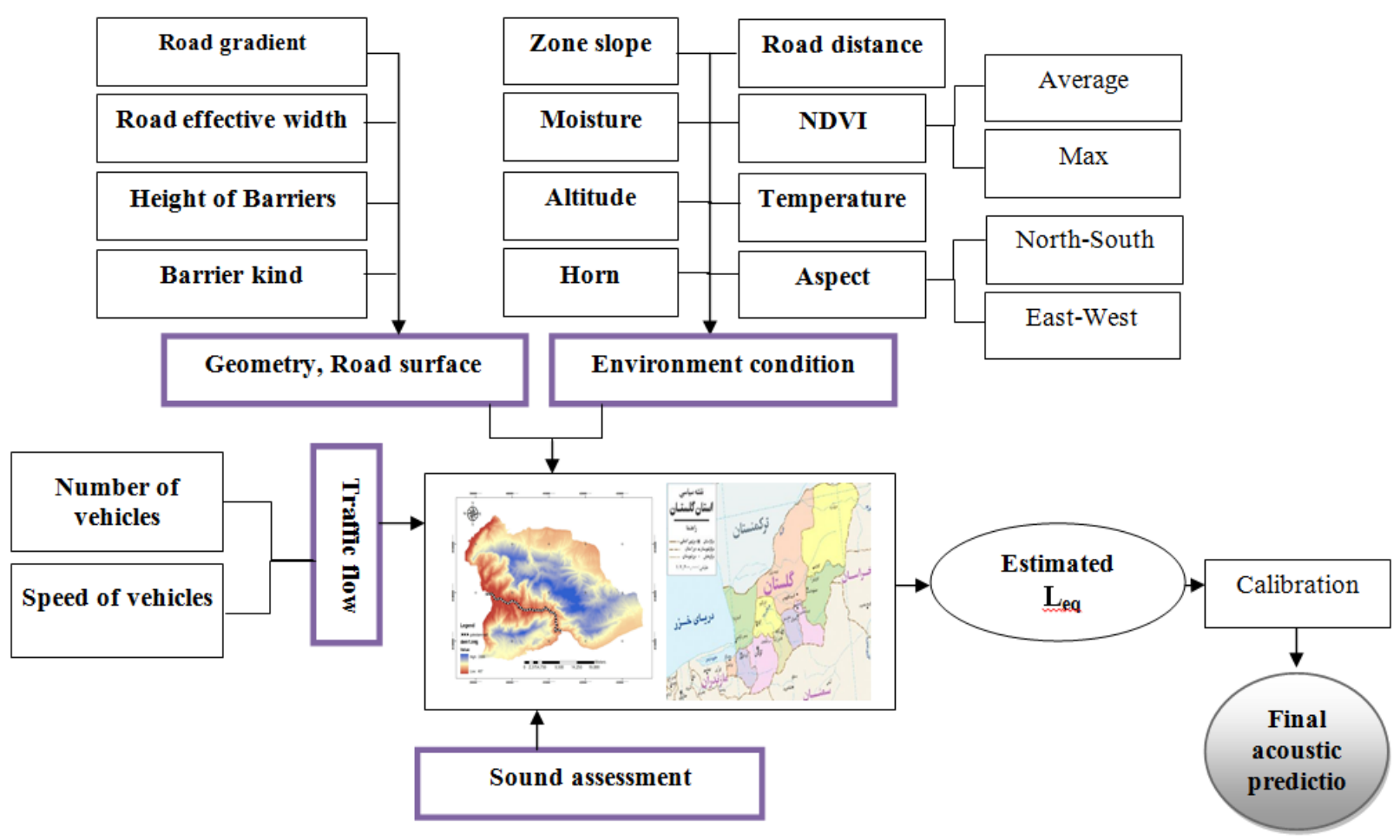

Figure 2. Flowchart of the operative process. 


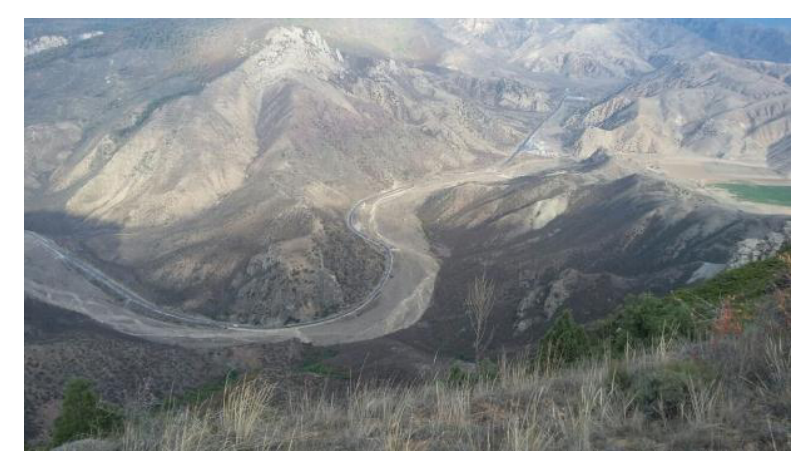

Figure 3. A view of the study area (Shiva Gharibi, 2011).

\subsection{Technique}

This study was conducted in September 2012, along the Asian Highway in Golestan National Park. The study was conducted during a week of the year with the heaviest traffic flows at various times from 8 am to $8 \mathrm{pm}$. At first the GIS software used to determine the unique area based on Digital elevation model (Dem), slope, aspect and Normalized Difference Vegetation Index (NDVI). Then 250 meter buffers were applied on two sides of the road and this zone contained 11 homogeneous regions. Using IDRISI software, sampling stations were selected in this area at 76 points using a systematic-random method at various distances between 0-250 metres from the main road (Fig. 4) and covered the entire Golestan road (26.51 $\mathrm{km})$.

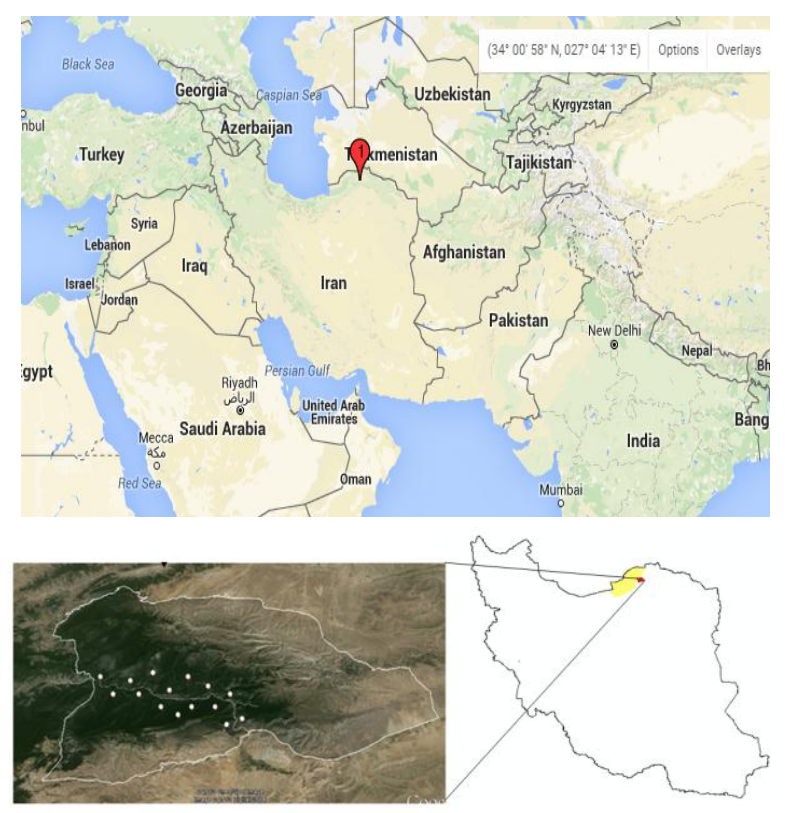

Figure 4. Location of Golestan national park and sampling stations.

Ref [12] at each sampling point, measurements of sound and other variables were taken at 15 minute intervals from 8 am to $8 \mathrm{pm}$. Sound level meter devices model CEL-450 were used for evaluating the dependent variable or Leq. Simultaneously 19 independent variables affecting the sound were also measured. The developed model has as many Independent variables as possible for estimation traffic noise (Leq). Three groups of variables were considered in the model, as shown in Table 1.
The number of vehicles was recorded using a video camera, and the speed of vehicles was measured using EDIUS 6 software and then physical formulations. By multiplying this numbers at 4 , number of vehicles and horns was obtained in 1hour. Measurement and data collection was performed in lack of rainfall and wind environmental conditions and each variable was measured within a circular plot and the centrality of the sampling point and others were measured at roadside. Fig. 5 shows some of the variables measured. Each of these variables makes a specific contribution to sound emission, but some may have a much larger role in the in spread of sound and some may have little role. Fig. 5.

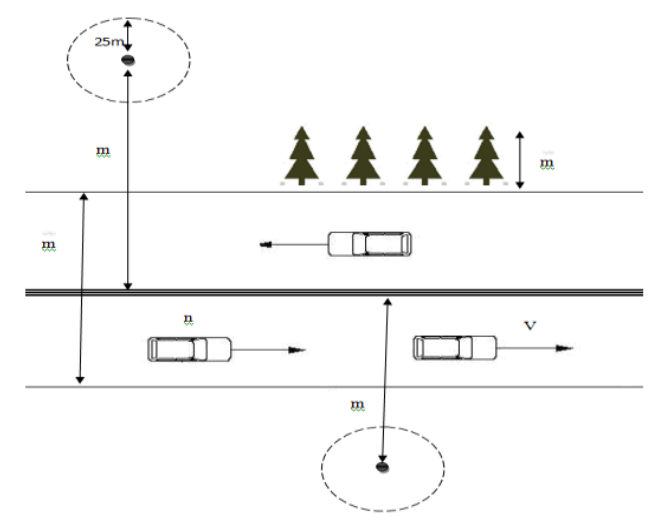

Figure 5. Graphic form of sampling plot.

\subsection{Model development}

Modelling based on $\mathrm{L}_{\mathrm{eq}}(1 \mathrm{~h})$ as the dependent variable and 19 other variables as independent variables was performed using SPSS software. To provide the best multivariate regression, the stepwise regression method was used with a correlation coefficient $(\mathrm{R})$ and the coefficient of determination $\left(\mathrm{R}^{2}\right)$. In the modelling, due to the high correlation coefficient $\mathrm{L}_{\mathrm{eq}}(15)$ instead of $\mathrm{L}_{\mathrm{eq}}(60)$ can be used [15]. Therefore, a model was developed for equivalent sound level (1h) and to evaluate the final model, data from 26 samples out of 76 samples were used for model validation.

Table I. Model inputs (Independent variables affecting the sound)

\begin{tabular}{|c|c|c|}
\hline A. Traffic flow & $\begin{array}{l}\text { B. Geometry of } \\
\text { road surface }\end{array}$ & $\begin{array}{ll}\text { C. } & \begin{array}{l}\text { Location } \\
\text { conditions }\end{array} \\
\end{array}$ \\
\hline 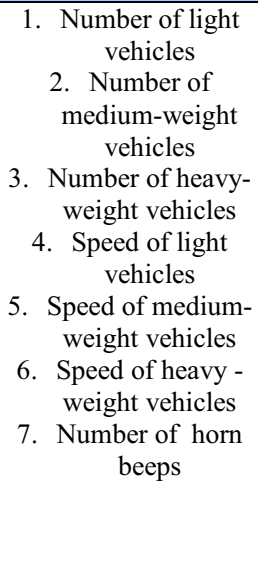 & $\begin{array}{cc}\text { 8. } & \text { Road slope (per } \\
\text { cent) } \\
\text { 9. } & \text { Road effective } \\
& \text { width }(\mathrm{m}) \\
\text { 10. } & \text { Noise barrier } \\
& \text { height }\end{array}$ & 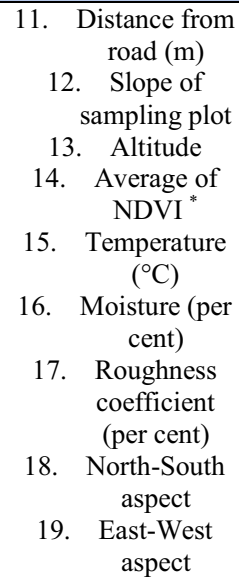 \\
\hline
\end{tabular}

"Normalized Difference Vegetation Index (NDVI) 


\section{Results}

The results showed that the noise level at all stations based on the equivalent sound level was 51-79 $\mathrm{dB}$. The values of equivalent sound levels at all stations are shown in Fig. 6.

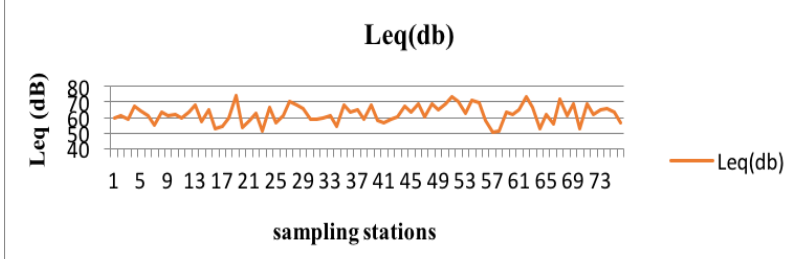

Figure 6. Equivalent sound level (Leq) at sampling stations

For the modelling, according to the goodness-of-fit test results, the best linear relationship between variables was determined. The result of multivariate linear regression analysis of the Leq $(1 \mathrm{~h})$ model is obtained with the correlation coefficient (R) and the coefficient of determination (R2) that is given as follows (Equation 1).

$$
\begin{gathered}
L_{e q}(1 \mathrm{~h})=75.61-14.2 \log \left(\operatorname{Road}_{\text {dis }}\right)+ \\
0.654 \log (\text { rugged })+0.018\left(V_{m}\right)+0.106 \\
(\text { Mois })+0.006(z)+0.005(\mathrm{Nl})
\end{gathered}
$$

where,

$\operatorname{Road}_{\text {dis }}$ : distance from a traffic line to receiving point $(\mathrm{m})$ Rugged: Ground roughness coefficient (per cent)

$\mathrm{V}_{\mathrm{m}}$ : Speed of medium-weight vehicles

Mois: Moisture (percent)

$\mathrm{Z}$ : Altitude (m)

$\mathrm{Nl}$ : Number of light vehicles

Table I shows that the R-square and the adjusted Rsquare of the regression equation were $73 \%$ and $68 \%$ respectively and Fig. 7 shows a comparison between measured Leq and predicted values based on the proposed model.

Table 2. Details of predicted model

\begin{tabular}{|ccccc|}
\hline $\begin{array}{l}\text { Mode } \\
1\end{array}$ & $\mathrm{R}$ & $\begin{array}{l}\mathrm{R} \\
\text { Square }\end{array}$ & $\begin{array}{l}\text { Adjusted } \\
\text { R Square }\end{array}$ & $\begin{array}{c}\text { Std. Error } \\
\text { of } \\
\text { Estimate }\end{array}$ \\
\hline 1 & 0.825 & 0.726 & 0.683 & 3.082 \\
\hline
\end{tabular}

Details of the statistical analysis as descriptive statistics (Table 2) and distribution of errors (Figure 7) are shown in Table 3.

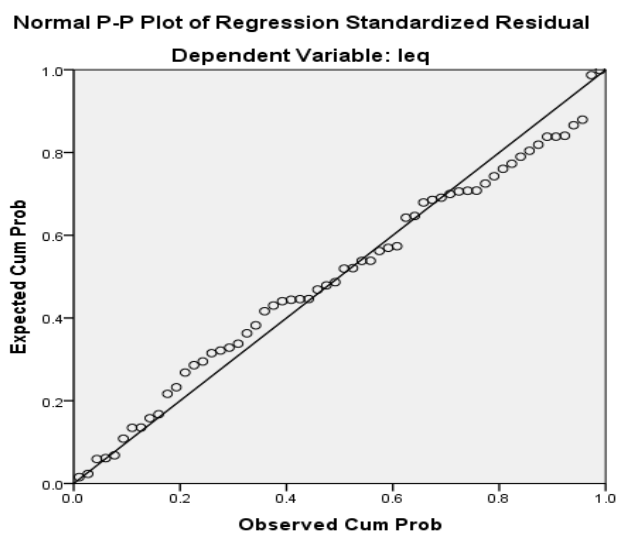

Figure 7. Scatter plot of predicted and measured values of Leq
Table 3. The details of predicted model

\begin{tabular}{|llll|}
\hline Variables & Mean & $\begin{array}{l}\text { Standar } \\
\text { d } \\
\text { deviatio } \\
\mathrm{n}\end{array}$ & $\begin{array}{l}\text { Number of } \\
\text { sampling } \\
\text { points }\end{array}$ \\
\hline $\begin{array}{l}\text { Equivalent sound } \\
\text { level }\end{array}$ & 62.27 & 5.472 & 60 \\
Temperature & 32.3512 & 4.599 & 60 \\
Relative humidity & 40.2072 & 15.1526 & 60 \\
Road effective width & 10.39 & 3.624 & 60 \\
Altitude & 749.78 & 166.364 & 60 \\
Aspect & 126.02 & 121.472 & 60 \\
$\begin{array}{l}\text { Average of NDVI } \\
\text { Road slope }\end{array}$ & 147.7856 & 49.69 & 60 \\
$\begin{array}{l}\text { Noise barrier height } \\
\text { Number of light }\end{array}$ & 27.57 & 13.308 & 60 \\
vehicles & 1.17 & 4.555 & 60 \\
$\begin{array}{l}\text { Number of medium- } \\
\text { weight vehicles }\end{array}$ & 99.61 & 28.045 & 60 \\
$\begin{array}{l}\text { Number of heavy- } \\
\text { weight vehicles }\end{array}$ & 67.97 & 22.065 & 60 \\
$\begin{array}{l}\text { Speed of light } \\
\text { vehicles }\end{array}$ & 165.53 & 94.211 & 60 \\
$\begin{array}{l}\text { Speed of medium- } \\
\text { weight vehicles }\end{array}$ & 138.23 & 83.841 & 60 \\
$\begin{array}{l}\text { Distance from road } \\
\text { (m) }\end{array}$ & 1.7412 & 0.29943 & 60 \\
$\begin{array}{l}\text { Slope of sampling } \\
\text { plot }\end{array}$ & 1.1401 & 0.46416 & 60 \\
$\begin{array}{l}\text { Speed of heavy - } \\
\text { weight vehicles }\end{array}$ & 1.7641 & 0.13691 & 60 \\
$\begin{array}{l}\text { Number of horn } \\
\text { beeping }\end{array}$ & 1.4122 & 0.36726 & 60 \\
Roughness coefficient & 0.1605 & 1.98613 & 60 \\
\hline & & & 60 \\
\hline
\end{tabular}

Based on the results, an acoustic zoning map was obtained by using the interpolation method for the Asian Highway in Golestan National, Park Fig. 8.

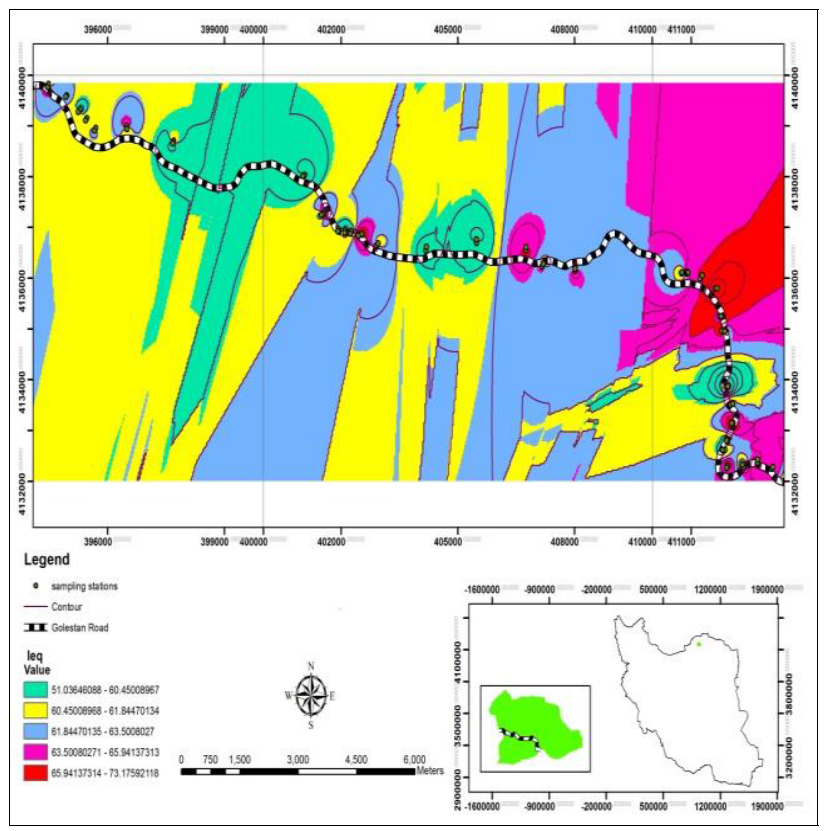

Figure 8. Zoning map of equivalent sound levels (Leq) in Golestan National Park 


\section{Conclusion}

The present study has introduced a model for the prediction of road traffic noise in Golestan National Park. This paper is the result of a study that was performed during 2012 in Iran. The data set consisted of 76 samples, utilized to develop a new model for national park conditions using regression analysis. The measurements show that there is serious noise pollution due to traffic in the park which is not in the acceptable range, according to policies of the Environmental Protection Agency of Iran. The results of modelling showed that the most important variables affecting noise pollution are distance from the road, roughness coefficient, speed of mediumweight vehicles, relative humidity, and height and number of light vehicles. There is a negative correlation with distance from the road and noise pollution. Environmental noise levels can vary over a wide range as a result of the diversity of site conditions and activities occurring during field measurements. However, this prediction model has been developed to predict the noise in a standard situation where the road surface is dry and there is no snow or ice on the terrain.

\section{Recommendation}

Highways and roads are one of the most important anthropogenic impacts on the environment and the noise generated by the speed of medium-weight vehicles and the number of light vehicles is the most annoying noise. It is an increasing environmental problem in terms of nuisance and annoyance to species in the communities around the highways in Golestan National Park and the increase in number and speed of vehicles on the roads has caused increasingly greater highway noise problems to the surrounding areas. Some bird species such as woodpeckers, nuthatches, robins, chaffinches and blackbirds are most sensitive to sound levels, but since the noise pollution is a slow killer for the community of birds, very little effort has been made to ameliorate the problem. Therefore, the developed regression model can be applied for all protected areas in the country, because the suggested model has a high coefficient of determination (73\%), which indicates the adequacy of the model.

\section{References}

1. Zannin, P. H. T.; Calixto, A. D. and Ferreira, J. A. , A survey of urban noise annoyance in a large Brazilian city. The importance of a subjective analysis in conjunction with an objective analysis, Journal of Environmental Impact Assessment Review, Vol 23, no 2, Pages 245-255, (2003).
2. Bendtsen, H. 1999. The Nordic prediction method for road traffic noise. Journal of Science of The Total Environment, Vol 235, no 1-3, 1, pp 331-338, September (1999)

3. Campbell, S.A. 2001. Critical Review of Some Traffic Noise Perdiction Models, Journal Applied Acoustics. Vol 62, no 3 , pp 271-287, (2001)

4. Gundogdu, O., Gokdag, M., Yuksel, F. 2005. A traffic noise prediction method based on vehicle composition using genetic algorithms. Journal of Applied Acoustics, Vol 66, no 7, pp 799-809, (2005).

5. Gulliver, J., Morley, D., Vienneau, D., Fabbri, F., Bell, M., Goodman, P., Beevers, S., Dajnak, D., Kelly, F. J. and Fecht, D. ,Development of an opensource road traffic noise model for exposure assessment, Journal of Environmental Modelling \& Software, Vol 74, pp 183-193, (2015)

6. Paz, E. C., Ferreira, A. M. C., and Zannin, P. H. T. ,Comparative study of the perception of urban noise. Journal of Public Health, Vol 39, no 3, pp 467-472, (2005)

7. Vincenzo, B., Crocco, F. and Mongelli, D.W.E., A mathematical model for traffic noise prediction in an urban area. 4th WSEAS International Conferense on Urban Planning and Transportation UPT2011." Corfu Island, Greece, pp 405-410, (2011)

8. Reed, S., Boggs, J. L. and Mann, j. p., A GIS tool for modeling anthropogenic noise propagation in natural ecosystems. Journal of Environmental Modelling \& Software, Vol 37, pp 1-5, (2012)

9. Majnonian, H.; Dehzad, B.; Farhang Dareshori, B and Maigoni, H. , Certificate of Golestan National Park. (in Persian.), (2000).

10. Darvish Sefat, A., Atlas of Protected Areas of Iran. University of Tehran Publications(Persian.), pp 5157, (2007)

11. Sohrabi, M. Lichens from Golestan National Park (Iran). Journal of Folia Crypotg, Fasc, Vol 41, pp 105-108, (2005).

12. Peris, S. J. and Pescador, M. 2004. Effects of traffic noise on passerine populations in Mediterranean wooded pastures. Applied Acoustics, Vol 65, pp 57366, (2004).

13. Samadyar, H, Effective Elemnts of Traffic Noise Control in the Urban Environment , II National Conference of Air plloution and Environmental Health (2007), Iran

14. Singh, N. and Davar, S. C. , Noise Pollution- Sources, Effects and Control. Journal of Hum. Ecol., Vol 16, no 3, pp 181-187, 2004

15. Zaree Chahoki, M. A., 2010, Data analysis in natural resources research using SPSS software. University of Tehran Press, Iran,1st ed, (2010). 